\title{
Still life
}

"There will be time to murder and create." T.S. Eliot

a leatherbound Bible

and the works of Louis L'Amour

bless every room

in his family's home

more strikingly,

some quarter million dollars worth of taxidermy fills the house

\& spills into specially-constructed, heated outbuildings

designed for display

every creeping thing that creepeth in his palette, framed within the crosshairs of a Bushnell scope, the powers of creation and destruction the same

snuffed

then

stuffed with obsessive reverence

the spirit breathed into these dried and salted hides

freed from the dull and constant search for food

the essential moment realized

the ecstasy

hundreds of glass eyes

sparkling ever more greatly

than in life 